\title{
Saudi Arabia Special Education Teachers' Attitudes Toward Assistive Technology Use For Students With Intellectual Disability
}

\author{
Sultan Aldehami \\ Department of Special Education, College of Science and Arts, Qassim University, Ar Rass, Saudi Arabia \\ ORCID: 0000-0002-3574-6449
}

Received: 30 Sep 2021

Accepted: 5 Jan 2022

\begin{abstract}
This study was conducted in the central region of the Kingdom of Saudi Arabia (KSA) to investigate levels of teachers' assistive technology (AT) knowledge and skills use in classrooms for students with intellectual disability (ID). A total of 98 special education teachers of students with ID completed an online survey. Results indicate that the teachers' levels of knowledge and skills related to AT use in classrooms for students with ID were reaching proficiency. Teachers' levels of AT knowledge and skills statistically significantly differed based on gender, training, level of education, teaching experience, and school location but not on grade level. However, there were statistically significant differences in teachers' professional development based on gender and teaching experience but not based on training, level of education, grade level, and school location. Furthermore, results indicate that teachers' perceptions of AT significantly predicted teachers' knowledge and skills related to AT use in educational environments.
\end{abstract}

Keywords: special education, intellectual disability, assistive technology, attitudes, special education teachers

\section{INTRODUCTION}

Technology is constantly changing, and has led to innovations that have improved many people's quality of life, including those with disabilities. The importance and effectiveness of teachers' use of assistive technologies (AT) to promote the academic and nonacademic success of students with disabilities cannot be understated. Alkahtani (2013) mentioned that negative beliefs and attitudes of teachers play an essential role in their avoidance of selecting or implementing AT for their students with disabilities while Flanagan et al. (2013) explained that teachers' attitudes were a significant predictor of teachers' selection and implementation of AT. Specifically, AT contributes to the development of students' performance in education by giving them opportunities to reach their full potential and live satisfying lives. Thus, AT has positively affected students in special education settings, allowing them to become more actively involved in their classrooms and to be more successful in other aspects of their lives (Erdem, 2017). Students with intellectual disabilities (ID) face many challenges and obstacles that reduce the extent of academic success they achieve because they need specific resources and aids that enable them to access information and curricula needed to succeed. Thus, AT is one of the most important aids that help students with disabilities succeed in education today (Bruinsma, 2011).

\section{LITERATURE REVIEW}

Alfaraj and Kuyini (2014) examined the types of technological tools that currently exist in schools for students with Down syndrome (DS) in Saudi Arabia, teachers' perceptions of technology, and solutions to improve the 
use of technology with students with DS. Teachers identified some challenges they faced in using technology such as lack of resources, software designed in Arabic, and training for teachers. Similarly, Alkahtani (2013) examined teachers' knowledge and use of AT for students with special educational needs, and indicated teachers' lack of knowledge and skills in using AT, which requires training teachers to increase their overall knowledge about AT. Also, Tamakloe and Agbenyega (2017) explored the experiences of preschool teachers and their support staff about the use of AT devices to support young students with disabilities in an inclusive preschool class. The results indicated a need for professional knowledge and practice in order to impact student learning. Moreover, many researchers have found that teachers' use of AT was very negligible despite the effect of AT with students with disabilities to access to the general curriculum (Bouck et al., 2012; Flanagan et al., 2013). Similarly, Alkahtani (2013) and Kurth and Keegan (2014) found that AT was one of the least used or considered by teachers in classrooms. additionally, Alkahtani (2013) indicated that $93 \%$ of teachers had no AT training but the majority of teachers expressed that they were interested in getting professional development in AT. In addition, Okolo and Diedrich (2014) examined 1,143 teachers in Michigan and found that the barrier that teachers expressed most related to their knowledge of AT use, beside some points such as accessibility to technology, limited funding, and implementation problems.

Researchers have reported that few teachers claimed they had the skills to use AT in their schools (Alkahtani, 2013; Ribeiro \& Moreira, 2010). This may be due to lack of training in types of AT or how to use it in educational settings (Flanagan et al., 2013). It follows that researchers also found that teachers who had taken college-level courses in AT had high levels of knowledge and use of AT (Bell et al., 2010; Van Laarhoven \& Conderman, 2011). In addition, Onivehu et al. (2017) found that neither gender nor years of teaching experience affected teachers' attitudes toward using AT.

Other researchers have found that rural schools were likely to face unique challenges compared to non-rural locations (Ault et al., 2013, Davis et al., 2013, Sutton et al., 2014). The results also revealed some barriers to using AT with students in rural schools related to lack of training, lack of funding, and limited time to work with AT. Lack of training or accessibility to AT could be due to the long distances required to travel within rural communities (Sibon-Macarro et al., 2014). Additionally, Almulla (2019) examined the overall level of 366 teachers' knowledge and skills related to using high-tech AT with students with learning disabilities in Saudi Arabia. Results indicated the level of teachers' knowledge and skills related to high-tech AT was approaching proficiency. Also, Almulla (2019) explained that gender impacted teachers' AT use and that teachers' perceptions of AT were a positive significant predictor of teachers' knowledge and skills. However, the results showed no significant differences in teachers' levels of knowledge and skills related to high-tech AT use based on school location, education level, and years of teaching experience.

Alkahtani (2013) mentioned that teachers' negative beliefs and attitudes play an essential role in their avoiding, selecting, or implementing AT. Flanagan et al. (2013) also explained that teachers' attitudes were a significant predictor of their selecting and implementing AT, and Yusuf and Fakomogbon (2008) found that teachers had positive attitudes toward using AT.

Not all studies have presented special education teachers' negative attitudes and lack of knowledge regarding AT. For instance, Alotaibi and Almalki (2016) found that Saudi teachers of students with Autism Spectrum Disorder had positive attitudes toward the use of information and communication technology (ICT). Similarly, Erdem (2017) conducted a literature review of studies using AT in the education of students with disabilities. Results clearly indicated that different types of AT were used in special education and that it had a positive effect on students with disabilities. Wojcik and Douglas (2012) emphasized that the effective use of AT is considered an essential factor in the educational process because it supports students' functional skills, such as reading, communication, and movement. All of these studies show the importance and effectiveness of using AT to support students' academic and nonacademic success.

\section{Definitions of Terms}

Special education is defined as specialized supports and services for learners with disabilities who qualify; it is for any individuals between the ages of 3 and 21 who attend educational institutions and get individualized instruction to meet their needs (Yell, 2016). 
Intellectual disability is a disability that is identified by significant limitations in both intellectual functioning and adaptive behavior. It is described as a situation in which mental performance is markedly less than the general average and is accompanied by a lack of two or more social and practical skills. Also, it occurs before reaching the age of 18 (Ministry of Education of Saudi Arabia, 2018).

Assistive technology (AT): AT is any device or service that helps a student with a disability meet his or her individualized education program (IEP) goals and participate in the general education setting to the greatest possible extent. To put it simply, AT improves the functional performance of an individual with a disability (The IRIS Center for Training Enhancements, 2010).

Attitude is defined as a feeling or way of thinking that affects a person's behavior (Merriam Webster Dictionary, n.d.).

\section{Problem Statement}

Currently, Saudi Arabia is interested in improving the education it provides for students with disabilities, and in recent decades, Saudi Arabia has witnessed remarkable development in providing quality services to children with disabilities (Battal, 2016). Moreover, Aldosari and Pufpaff (2014) mentioned that, despite Saudi Arabia's progress in developing special education, these services are still weak. Furthermore, there are some teachers who have negative feelings regarding the school services their students receive, including AT services. This may be because teachers lack knowledge about types of AT or fear using AT with their students. In the United States, under the Individuals with Disabilities Education Act (IDEA), students have the right to receive services but face significant obstacles due to teachers' low expectations and insufficient knowledge and understanding of special education services (Applequist, 2009).

Utley et al. (2011) called for researchers to show examples and evidence of AT that has been used effectively in school to help students with ID. Many researchers have studied teachers' perspectives on general education and categories of special education in Saudi Arabia, but only a few studies have examined teachers' knowledge and skills related to AT use for students with ID in the Saudi Arabia context. Unfortunately, researchers have not yet given this topic sufficient attention, so there is a need for investigation into the knowledge and skills of special education teachers teaching students with ID in Saudi Arabia regarding AT use in the classroom environment.

\section{Purpose of the Study}

There is a clear need to know levels of teachers' knowledge and skills related to AT use in classrooms for students with ID and to learn how they perceive AT supports and services for their students. This study examined teachers' attitudes toward AT use for students with ID in the central region of Saudi Arabia by investigating and understanding the overall levels of Saudi teachers' knowledge and skills related to using AT, by describing differences in these levels based on demographic characteristics, and by determining if teachers' perceptions of AT are a significant predictor of teachers' knowledge and skills related to using AT for students with ID in Saudi Arabia.

\section{Research Questions and Analyses}

This study was guided by the following overarching research question: What are Saudi Arabia special education teachers' attitudes toward assistive technology use for students with intellectual disabilities in the Qassim region? Four sub-questions were addressed in this study:

1. What is the level of teachers' knowledge and skills of assistive technology use in classrooms for students with intellectual disabilities in Saudi Arabia?

2. What are the differences in Saudi teachers' knowledge and skills related to assistive technology based on demographic characteristics of gender, training, level of education, years of experience, grade level, and school location? 
3. What are the differences in Saudi teachers' professional development related to assistive technology use based on demographic characteristics of gender, training, level of education, years of experience, grade level, and school location?

4. To what extent do teachers' perceptions of assistive technology predict teachers' knowledge and skills related to assistive technology for students with intellectual disabilities in Saudi Arabia?

\section{METHOD}

\section{Research Design and Sampling Methods}

This study used a non-experimental cross-sectional survey to collect data. Teddlie and Tashakkori (2009) defined quantitative research as the method primarily used in collecting, analyzing, interpreting, and presenting numerical information. Thus, an online survey was used to examine teachers' attitudes toward AT use for students with ID in the central region of Saudi Arabia, to investigate and understand the overall levels of teachers' knowledge and skills related to using AT, to describe differences across demographic characteristics, and to determine if teachers' perceptions of AT were a significant predictor of their knowledge and skills related to using AT for students with ID in Saudi Arabia. The survey included 34 questions divided into three sections: knowledge and skills, professional development, and perception of AT. Each section asked special education teachers specific questions related to AT. A simple random sampling was used; this is one type of quantitative sampling strategy from probability sampling. It is the most popular strategy for probability sampling from a population and, for this study, it gave equal opportunity to all teachers in Qassim State to be chosen from the population and participate in the study (Creswell, 2012). The sample included 98 special education teachers of students with ID who lived in the central region of Saudi Arabia.

\section{Instruments}

The researcher used two types of instruments to collect data from the participants: a demographic questionnaire and a survey. The demographic questionnaire included teacher's gender, training, level of education, years of teaching experience, grade level, and school location (i.e., large city, small city, or suburban region). The survey was a modified version of the Special Education Teachers' High-Tech Assistive Technology Skills and Knowledge Survey originally developed by Almulla (2019). It included 34 questions divided into three sections: knowledge and skills, professional development, and perception of AT. In brief, to measure content validity, a small group of three experts in the area of special education at the Qassim University reviewed the instrument.

\section{Data Analysis}

To answer RQ1, RQ2, and RQ3, the researcher used descriptive statistics including frequencies, means, standard deviations (SD), and percentages for all variables. RQ2 also focused on examining differences based on some variables, including gender and training in AT. The researcher conducted a t test of independent samples because there were two groups: males and females for gender, and yes and no for training. The researcher ran a comparative analysis using ANOVA for the education level, years of experience, grade level, and school location variables to determine the relation between these demographic characteristics and teachers' knowledge and skills regarding AT use.

RQ3 also focused on examining differences based on some variables, including gender and training in AT. The researcher conducted a t test of independent samples because there were two groups: males and females for gender, and yes and no for training. The researcher conducted comparative analysis using ANOVA for the education level, years of experience, grade level, and school location variables to determine the relation between these demographic characteristics and teachers' professional development regarding AT use. The researcher used linear regression analysis to answer RQ4. The one predictor (independent) variable was teachers' perceptions of AT. The outcome (dependent) variable was teachers' levels of knowledge and skills. 
Table 1. Internal consistency reliability coefficients in Cronbach's alpha

\begin{tabular}{lcc}
\hline Subscales & Number of items & $\begin{array}{c}\text { Reliability coefficient } \\
\text { Current study }\end{array}$ \\
\hline Knowledge and skills & 13 & .89 \\
Professional development & 4 & .71 \\
Processes & 11 & .72 \\
Total & 28 & .85 \\
\hline
\end{tabular}

Table 2. Demographics of the teacher respondents

\begin{tabular}{|c|c|c|}
\hline Variables & $\begin{array}{c}(\mathrm{N}=98) \\
\text { Frequency }\end{array}$ & Percentage (\%) \\
\hline \multicolumn{3}{|l|}{ Gender } \\
\hline Male & 51 & 52 \\
\hline Female & 47 & 48 \\
\hline \multicolumn{3}{|l|}{ Education level } \\
\hline Diploma & 8 & 8.2 \\
\hline Completed Bachelor's degree & 75 & 76.5 \\
\hline Completed Master's degree & 10 & 10.2 \\
\hline Completed PhD degree & 5 & 5.1 \\
\hline \multicolumn{3}{|l|}{ Teaching experience } \\
\hline $5-10$ years & 38 & 38.8 \\
\hline $11-16$ years & 36 & 36.7 \\
\hline Over 16 years & 24 & 24.5 \\
\hline \multicolumn{3}{|l|}{ Training in assistive technology } \\
\hline Yes & 27 & 27.6 \\
\hline No & 71 & 72.4 \\
\hline \multicolumn{3}{|l|}{ Grade level } \\
\hline Elementary & 57 & 58.2 \\
\hline Middle & 15 & 15.3 \\
\hline High & 26 & 26.5 \\
\hline \multicolumn{3}{|l|}{ School location } \\
\hline Large city & 31 & 31.6 \\
\hline Small city & 56 & 57.1 \\
\hline Suburban region & 11 & 11.2 \\
\hline
\end{tabular}

\section{RESULTS}

\section{Reliability Data Collection}

Table 1 shows the internal consistency/reliability in Cronbach's alpha conducted for each dependent variable's (DV) scale and on the entire scale as the first step before conducting the statistical analysis to answer the research questions. Reliability coefficients in the three subscales reported were .71, .72, and .89. Moreover, the internal consistency reliability in Cronbach's alpha on the entire scale was conducted on the 28 items and indicated that the total reliability coefficient was .85 which indicated acceptability.

\section{Descriptive Analysis Results}

Table 2 shows the demographic characteristics of 98 special education teachers who taught students with ID in the central region of Saudi Arabia. Regarding gender, 52\% who completed the survey were male, and $48 \%$ were female. Furthermore, most of the teachers (76.5\%) had earned bachelor's degrees, $10.2 \%$ had earned Master's degrees, $8.2 \%$ had completed Diploma programs, and 5.1\% had earned doctoral degrees. Also, $38.8 \%$ of the teachers ranged their teaching experiences between 5 and 10 years, other teachers (36.7\%) ranged their teaching experiences between 11 and 16 years, and some teachers (24.5\%) ranged their teaching experiences over 16 years. Regarding training in AT, a majority of the teachers (72.4\%) had not received any training in AT while $27.6 \%$ had received some AT training. Regarding grade level, most of the 
Table 3. Descriptive analysis of four knowledge and skills items (Ks)

\begin{tabular}{|c|c|c|c|}
\hline & Response & Frequency & Percentage (\%) \\
\hline \multirow[t]{4}{*}{ Ks-training } & Friends & 24 & 24.5 \\
\hline & Online training & 23 & 23.5 \\
\hline & Workshops & 24 & 24.5 \\
\hline & None & 27 & 27.6 \\
\hline \multirow[t]{4}{*}{ Ks-knowledge } & None & 10 & 10.2 \\
\hline & Beginner & 53 & 54.1 \\
\hline & Proficient & 26 & 26.5 \\
\hline & Excellent/Expert & 9 & 9.2 \\
\hline \multirow[t]{4}{*}{ Ks-skills } & None & 11 & 11.2 \\
\hline & Beginner & 50 & 51.0 \\
\hline & Proficient & 30 & 30.6 \\
\hline & Excellent/Expert & 7 & 7.1 \\
\hline \multirow[t]{2}{*}{ Ks-others } & Yes & 33 & 33.7 \\
\hline & No & 65 & 66.3 \\
\hline
\end{tabular}

Ks: Knowledge and skills

teachers (58.2\%) indicated that they currently taught in elementary school, $26.5 \%$ taught in high school, and some (15.3\%) taught in middle school. In regard to the school location variable, half of the teachers indicated that their schools were located in small cities $(57.1 \%)$, over a quarter said their schools were located in large cities (31.6\%), and $11.2 \%$ indicated that their schools were located in suburban regions.

Table 3 displays descriptive analysis results for four survey items on knowledge and skills. Results of the first item coded as Ks-training: I have received informal or formal training regarding implementing and using various types of assistive technology (AT) indicate that $27.6 \%$ of the teachers had no training, $23.5 \%$ had online training, and $24.5 \%$ had received training via friends or workshops. The second item coded as Ksknowledge: Estimate your knowledge about using various types of $A T$ indicated that more than half of the teachers had beginner knowledge (54.1\%), a quarter (26.5\%) evaluated themselves as proficient, a few (9.2\%) had excellent or expert knowledge, and $10.2 \%$ of the teachers had no knowledge. Additionally, the item coded as Ks-skills: Estimate your skill level of implementing various types of AT showed that about half of the teachers (51\%) had beginner skills, $30.6 \%$ identified as proficient, a few $(7.1 \%)$ had excellent or expert skills while $11.2 \%$ had no skills. Lastly, for the item coded as (Ks-others): I work with others, including IEP team implementation members, in selecting and implementing AT, two-thirds of the teachers (66.3\%) expressed that they didn't work with others while $33.7 \%$ said they had worked with others in this capacity.

\section{Results Related to RQ1}

\section{Knowledge and skills}

Table 4 displays the means and SD of the Knowledge and Skills (ks) scale results regarding the teachers' estimation of their expertise in the use of AT. The item coded as (ks-4): I know how to arrange the classroom environment to facilitate the use of $A T$ yielded the highest mean score $(M=2.39)$ among all the ks items. In contrast, the item coded as (ks-7): I know how to use a variety of AT devices to support students with intellectual disabilities indicated the lowest mean score $(M=2.19)$ among all other ks items. Furthermore, the item coded as (ks-3): I have the knowledge to assess students with intellectual disabilities to determine what $A T$ would be appropriate for them showed the greatest dispersion $(\mathrm{SD}=.808)$ among all other ks items whereas the item coded as (ks-2): I am confident in my ability to identify and operate software programs that meet students with intellectual disabilities' IEP goals indicated the least variation $(S D=.700)$ among all ks items. 
Table 4. Item means and standard deviations (SD) of the knowledge and skills (Ks) scale

\begin{tabular}{|c|c|c|}
\hline Item code & Mean & SD \\
\hline Ks-1: I know the concepts, terms, and laws in Saudi Arabia about AT & 2.31 & .752 \\
\hline $\begin{array}{l}\text { Ks-2: I am confident in my ability to identify and operate software programs that meet students with } \\
\text { intellectual disabilities' IEP goals }\end{array}$ & 2.28 & .700 \\
\hline $\begin{array}{l}\text { Ks-3: I have the knowledge to assess students with intellectual disabilities to determine what AT would } \\
\text { be appropriate for them }\end{array}$ & 2.13 & .808 \\
\hline Ks-4: I know how to arrange the classroom environment to facilitate the use of AT & 2.39 & .782 \\
\hline $\begin{array}{l}\text { Ks-5: I am qualified to evaluate whether AT is effective in meeting the needs of my students with } \\
\text { intellectual disabilities }\end{array}$ & 2.34 & .786 \\
\hline $\begin{array}{l}\text { Ks-6: I am confident in my ability to identify a variety of AT tools that my students with intellectual } \\
\text { disabilities need }\end{array}$ & 2.28 & .715 \\
\hline Ks-7: I know how to use a variety of AT devices to support students with intellectual disabilities & 2.19 & .727 \\
\hline Ks-8: I follow a systematic plan to ensure that AT is correctly impler & 2.37 & .792 \\
\hline Ks-9: I know how to identify resources for professional training and development & 2.38 & .753 \\
\hline
\end{tabular}

Ks: Knowledge and skills

Table 5. Item means and standard deviations (SD) of the professional development (pd) scale

\begin{tabular}{|c|c|c|}
\hline Item code & Mean & SD \\
\hline pd-1: Are you interested in receiving more knowledge and skill related to AT? & .07 & .259 \\
\hline pd-2: Which academic area are you MOST interested in for AT? & 2.57 & 1.103 \\
\hline pd-3: Based on your learning style, please select your MOST preferred method for AT training. & 1.91 & .558 \\
\hline pd-4: When do you prefer to receive your training? & 2.66 & 1.218 \\
\hline
\end{tabular}

pd: Professional development

\section{Professional development}

Table 5 displays the means and SD of the Professional Development (pd) scale regarding the teachers' estimation of their expertise in the use of AT. The item coded as ( $p d-4)$ : When do you prefer to receive your training? yielded the highest mean score $(M=2.66, S D=1.218)$ among all pd items. In contrast, the item coded as ( $p d-1)$ : Are you interested in receiving more knowledge and skill related to the various types of AT? indicated the lowest mean score $(M=.07, S D=.259)$ among all pd items.

\section{Perceptions of $A T$}

Table 6 displays the means and SD of the Perceptions of AT (per) scale regarding the teachers' estimation of their expertise in the use of AT. The item coded as (per-4): Professionals should conduct AT evaluation regularly to determine whether or not their students need AT devices resulted in the highest mean score $(M=3.40)$ among all per items. In contrast, the item coded as (per-6): I feel anxious about $A T$, thus I rarely use it indicated the lowest mean score $(\mathrm{M}=2.52)$ among all per items. Regarding the dispersion of the scores, the item coded as (per-6): I feel anxious about AT, thus I rarely use it, showed the highest variation (SD=.922) among all per items whereas the item coded as (per-3): I will use AT devices for my teaching as well as learning indicated the lowest variation $(S D=.489)$ among per items.

\section{Results Related to RQ2}

\section{T-test results}

The researcher conducted an independent $t$ test to explore differences between male and female teachers on their AT knowledge and skills. As shown in Table 7, the independent $t$ test indicated no significant difference between males $(M=20.27, S D=5.77)$ and females $(M=21.06, S D=5.26)$ on their knowledge and skills, $\mathrm{t}(96)=-.705, \mathrm{p}=.48$. For the second variable, the researcher conducted an independent $t$ test to explore differences between teachers if they had any training or not in AT based on their knowledge and skills. Thus, the independent $t$ test indicated a statistically significant difference between teachers who had previous 
Table 6. Item means and standard deviations (SD) of the perceptions of AT (per) scale

\begin{tabular}{|c|c|c|}
\hline Item code & Mean & SD \\
\hline $\begin{array}{l}\text { per-1: Students with disabilities usually use AT to access and use standard tools, participate in learning } \\
\text { activities, and complete educational tasks }\end{array}$ & 2.78 & .618 \\
\hline $\begin{array}{l}\text { per-2: I would recommend the use of AT to my colleagues because it is more than a mere educational } \\
\text { tool }\end{array}$ & 3.27 & .602 \\
\hline per-3: I will use AT devices for my teaching as well as learning & 3.32 & .489 \\
\hline $\begin{array}{l}\text { per-4: Professionals should conduct AT evaluation regularly to determine whether or not their students } \\
\text { need AT devices }\end{array}$ & 3.40 & .513 \\
\hline per-5: I plan to use AT in the next 5 months & 3.33 & .513 \\
\hline per-6: I feel anxious about AT, thus I rarely use it & 2.52 & .922 \\
\hline per-7: I find AT very useful in performing my job & 3.34 & .496 \\
\hline per-8: I like working with AT devices & 3.28 & .513 \\
\hline per-9: Using AT devices helps me increase student productivity & 3.26 & .504 \\
\hline per-10: My colleagues, being influential, think I should use AT devices frequently & 2.91 & .644 \\
\hline per-11: If I get stuck using AT, I can call a technician for help & 3.26 & .562 \\
\hline
\end{tabular}
per: perception

Table 7. Means, SD, and results of t-test for teachers' responses depending on gender and training variables

\begin{tabular}{lccccccc}
\hline Variables & & $\mathrm{N}$ & Mean & SD & $\mathrm{T}$ & $\mathrm{df}$ & Sig. \\
\hline Gender & Male & 51 & 20.27 & 5.77 & -.705 & 96 & .48 \\
& Female & 47 & 21.06 & 5.26 & & & \\
\hline Training & Yes & 27 & 24.70 & 5.03 & 4.99 & 96 & .000 \\
& No & 71 & 19.11 & 4.91 & & & \\
\hline
\end{tabular}

training $(M=24.70, S D=5.03)$ and teachers who had no previous training $(M=19.11, S D=4.91)$ on their $A T$ knowledge and skills, $\mathrm{t}(96)=4.99, \mathrm{p}=.001$.

\section{Results of analysis of variance (ANOVA)}

As shown in Table 8, one-way ANOVA results show that the teachers' levels in knowledge and skills related to AT were statistically significantly different based on levels of education, $F(3,94)=4.25, p=0.007$. Thus, the teachers' levels of AT knowledge and skills were slightly increased based on mean scores: diploma ( $M=17.37$, $S D=4.24)$, bachelor's $(M=20.26, S D=5.49)$, master's $(M=23, S D=3.55)$, and doctoral $(M=27, S D=5.74)$.

For the years of teaching experience variable, one-way ANOVA results indicate that the teachers' levels of AT knowledge and skills were statistically significantly different based on their years of teaching experience, $F(2$, $95)=4.24, p=0.017$, as shown in Table 8. Thus, the teachers' levels of AT knowledge and skills were slightly increased based on mean scores: over 16 years $(M=17.96, S D=5.76), 11-16$ years $(M=21.11, S D=4.54)$, and 510 years $(M=21.92, S D=5.76)$.

For the grade level variable, one-way ANOVA results indicating that the teachers' levels of AT knowledge and skills were not statistically significantly different based on the grade levels they taught, $F(2,95)=.390, p=.678$, as shown in Table 8. Thus, the teachers' levels of AT knowledge and skills were slightly increased based on mean scores: high school $(M=20, S D=5.56)$, middle school $(M=20.20, S D=7.58)$, and elementary school $(\mathrm{M}=21.07, \mathrm{SD}=4.92)$.

For the school location variable, one-way ANOVA results indicating that the teachers' levels of AT knowledge and skills were statistically significantly different based on school location, $F(2,95)=4.13, p=.019$ as shown in Table 8. Thus, the teachers' levels of AT knowledge and skills were slightly increased based on mean scores as follows: suburban region $(M=16.54, S D=3.58)$, small city $(M=20.75, S D=5.80)$, and large city $(M=21.93$, $\mathrm{SD}=4.97)$. 
Table 8. Means, SD, and results of analysis of variance (ANOVA) for teachers' responses based on education level, teaching experience, grade level, and school location variables

\begin{tabular}{lccccccccc}
\hline Variable & & $\mathrm{N}$ & Mean & SD & & Sum of squares & df & $\mathrm{F}$ & Sig. \\
\hline Level of & Diploma & 8 & 17.37 & 4.24 & Between G. & 353.662 & 3 & 4.251 & .007 \\
education & Bachelor's & 75 & 20.26 & 5.49 & Within G. & 2606.542 & 94 & & \\
& Master's & 10 & 23 & 3.55 & Total & 2960.204 & 97 & & \\
& Doctoral & 5 & 27 & 5.74 & & & & & \\
Teaching & $5-10$ years & 38 & 21.92 & 5.76 & Between G. & 242.927 & 2 & 4.247 & .017 \\
experience & $11-16$ years & 36 & 21.11 & 4.54 & Within G. & 2717.277 & 95 & & \\
& Over 16 years & 24 & 17.95 & 5.76 & Total & 2960.204 & 97 & & \\
\hline Grade level & Elementary & 57 & 21.07 & 4.92 & Between G. & 24.085 & 2 & .390 & .678 \\
& Middle & 15 & 20.20 & 7.58 & Within G. & 2936.119 & 95 & & \\
& High & 26 & 20 & 5.56 & Total & 2960.204 & 97 & & \\
School location & Large city & 31 & 21.93 & 4.97 & Between G. & 237.106 & 2 & 4.136 & .019 \\
& Small city & 56 & 20.75 & 5.80 & Within G. & 2723.098 & 95 & & \\
& Suburban region & 11 & 16.54 & 3.58 & Total & 2960.204 & 97 & & \\
\hline
\end{tabular}

Table 9. Post hoc analysis (Bonferroni test) for teachers' responses based on education level variable

\begin{tabular}{|c|c|c|c|c|}
\hline Variables & & Mean difference & Std. error & Sig. \\
\hline \multicolumn{5}{|c|}{ Education level } \\
\hline \multirow[t]{3}{*}{ Diploma } & Bachelor & $-2.89167-$ & 1.95854 & .859 \\
\hline & Master & $-5.62500-$ & 2.49781 & 160 \\
\hline & Doctoral & $-9.62500-*$ & 3.00200 & .011 \\
\hline \multirow[t]{3}{*}{ Bachelor's } & Diploma & 2.89167 & 1.95854 & .859 \\
\hline & Master & $-2.73333-$ & 1.77275 & .759 \\
\hline & Doctoral & $-6.73333-^{*}$ & 2.43219 & .041 \\
\hline \multirow[t]{3}{*}{ Master's } & Diploma & 5.62500 & 2.49781 & 160 \\
\hline & Bachelor & 2.73333 & 1.77275 & .759 \\
\hline & Doctoral & $-4.00000-$ & 2.88422 & 1.000 \\
\hline \multirow[t]{3}{*}{ Doctoral } & Diploma & $9.62500 *$ & 3.00200 & .011 \\
\hline & Bachelor & $6.73333^{*}$ & 2.43219 & .041 \\
\hline & Master & 4.00000 & 2.88422 & 1.000 \\
\hline
\end{tabular}

Table 10. Post hoc analysis (Bonferroni test) for teachers' responses based on teaching experience variable

\begin{tabular}{lcccc}
\hline Variables & & Mean difference & Std. error & Sig. \\
\hline Teaching experience & & & & \\
\hline $5-10$ years & $11-16$ years & .80994 & 1.24388 & 1.000 \\
& over 16 years & $3.96272^{*}$ & 1.39445 & .016 \\
\hline $11-16$ years & $5-10$ years & $-.80994-$ & 1.24388 & 1.000 \\
& over 16 years & 3.15278 & 1.40937 & .083 \\
\hline Over 16 years & $5-10$ years & $-3.96272-*$ & 1.39445 & .016 \\
& $11-16$ years & $-3.15278-$ & 1.40937 & .083 \\
\hline
\end{tabular}

\section{Post hoc analysis (Bonferroni test) for teachers' responses based on education level, teaching experience, grade level, and school location variables}

Table 9 displays results of the Bonferroni test analysis indicating statistically significant differences between the teachers' levels of AT knowledge and skills based on their education levels. Teachers who had diplomas only were significantly different $(p=0.01)$ in AT knowledge and skills from teachers who had doctoral degrees. In addition, teachers who had bachelor's degrees were significantly different $(p=0.04)$ from teachers who had doctoral degrees. However, there was no statistically significant difference between other teachers' education levels.

Table 10 displays results of the Bonferroni test analysis indicating that there was only one statistically significant difference between the teachers' levels of AT knowledge and skills based on their years of teaching 
Table 11. Post hoc analysis (Bonferroni test) for teachers' responses based on grade level variable

\begin{tabular}{lcccc}
\hline Variables & & Mean difference & Std. error & Sig. \\
\hline Grade level & & & & 1.000 \\
Elementary & Middle & .87018 & 1.61327 & 1.000 \\
& High & 1.07018 & 1.31565 & 1.000 \\
Middle & Elementary & $-.87018-$ & 1.61327 & 1.000 \\
& High & .20000 & 1.80254 & 1.000 \\
High & Elementary & $-1.07018-$ & 1.31565 & 1.000 \\
& Middle & $-.20000-$ & 1.80254 & \\
\hline
\end{tabular}

Table 12. Post hoc analysis (Bonferroni test) for teachers' responses based on school location variable

\begin{tabular}{lcccc}
\hline Variables & & Mean difference & Std. error & Sig. \\
\hline School location & & & & \\
Large city & Small city & 1.18548 & 1.19855 & .975 \\
& Suburban regions & 5.39003 & 1.87896 & .015 \\
Small city & Large city & $-1.18548-$ & 1.19855 & .975 \\
& Suburban regions & 4.20455 & 1.76570 & .058 \\
Suburban region & Large city & $-5.39003-$ & 1.87896 & .015 \\
& Small city & $-4.20455-$ & 1.76570 & .058 \\
\hline
\end{tabular}

Table 13. Means, SD, and results of t-tests for teachers' responses based on gender and training variables

\begin{tabular}{lccccccc}
\hline Variables & & $\mathrm{N}$ & Mean & Std. & $\mathrm{T}$ & $\mathrm{df}$ & Sig. \\
\hline Gender & Male & 51 & 6.86 & 1.84 & -1.99 & 96 & .04 \\
& Female & 47 & 7.59 & 1.78 & & & \\
Training & Yes & 27 & 6.92 & 1.46 & -.95 & 96 & .34 \\
& No & 71 & 7.32 & 1.96 & & & \\
\hline
\end{tabular}

experience. Teachers who had 5-10 years of teaching experience were significantly different $(p=0.016)$ from teachers who had over 16 years of teaching experience. However, there was no statistically significant difference based on teachers' other years of teaching experience.

For the grade level variable, the results of the Bonferroni test analysis were not needed because they were not statistically significantly different based on the grade levels the teachers taught, as shown in Table 11.

Table 12 displays results of the Bonferroni test analysis indicating that there were statistically significant differences between the teachers' levels of AT knowledge and skills based on the locations of their schools. Teachers who taught in large cities were significantly different $(p=.01)$ from teachers who taught in suburban regions. In addition, teachers who taught in small cities were marginally significantly different $(p=.05)$ from teachers who taught in suburban regions. However, there were no statistically significant differences among other teachers based on the locations of their schools.

\section{Results Related to RQ3}

\section{$T$-test results}

The researcher conducted an independent $t$ test to explore differences between male and female teachers in their professional development. Thus, as shown in Table 13, the independent $t$ test indicated a statistically significant difference between males $(M=6.86, S D=1.84)$ and females $(M=7.59, S D=1.78)$ in their professional development, $t(96)=-1.99, p=.04$. For the second variable, the researcher conducted an independent $t$ test to explore differences in professional development between teachers who had any AT training and those who had no AT training. The independent t-test indicated no significant difference in professional development, $\mathrm{t}(96)=-.95, \mathrm{p}=.34$, between teachers who had previous $\mathrm{AT}$ training $(\mathrm{M}=6.92, \mathrm{SD}=1.46)$ and teachers who had no previous training $(M=7.32, S D=1.96)$. 
Table 14. Means, SS, and results of analysis of variance (ANOVA) for teachers' responses based on education level, teaching experience, grade level, and school location variables

\begin{tabular}{|c|c|c|c|c|c|c|c|c|c|}
\hline Variable & & $\mathrm{N}$ & Mean & SD & & Sum of squares & $\mathrm{df}$ & $F$ & Sig. \\
\hline \multirow[t]{4}{*}{ Education level } & Diploma & 8 & 8.75 & 1.48 & Between G. & 21.380 & 3 & 2.167 & .097 \\
\hline & Bachelor's & 75 & 7.12 & 1.92 & Within G. & 309.120 & 94 & & \\
\hline & Master's & 10 & 6.90 & 1.37 & Total & 330.500 & 97 & & \\
\hline & Doctoral & 5 & 6.80 & .836 & & & & & \\
\hline Teaching & $5-10$ years & 38 & 6.71 & 1.92 & Between G. & 21.629 & 2 & 3.326 & .040 \\
\hline \multirow[t]{2}{*}{ experience } & $11-16$ years & 36 & 7.27 & 1.83 & Within G. & 308.871 & 95 & & \\
\hline & Over 16 years & 24 & 7.9167 & 1.52 & Total & 330.500 & 97 & & \\
\hline \multirow[t]{3}{*}{ Grade level } & Elementary & 57 & 6.87 & 2.04 & Between G. & 15.488 & 2 & 2.335 & .102 \\
\hline & Middle & 15 & 7.66 & 1.04 & Within G. & 315.012 & 95 & & \\
\hline & High & 26 & 7.69 & 1.61 & Total & 330.500 & 97 & & \\
\hline \multirow[t]{3}{*}{ School location } & Large city & 31 & 7.35 & 1.85 & Between G. & 1.096 & 2 & .158 & .854 \\
\hline & Small city & 56 & 7.12 & 1.70 & Within G. & 329.404 & 95 & & \\
\hline & Suburban region & 11 & 7.27 & 2.57 & Total & 330.500 & 97 & & \\
\hline
\end{tabular}

\section{Results of analysis of variance (ANOVA)}

Results of a one-way ANOVA indicate that the teachers' levels of professional development related to AT were not statistically significantly different based on level of education, $F(3,94)=2.16, p=.09$. As shown in Table 14, the teachers' levels of professional development related to AT were slightly different based on education level mean scores: doctoral $(M=6.80, S D=.83)$, master's $(M=6.90, S D=1.37)$, bachelor's $(M=7.12$, $\mathrm{SD}=1.92)$, and diploma ( $M=8.75, \mathrm{SD}=1.48)$. Results of the Bonferroni test analysis were not needed, as shown in Table 15.

For the years of teaching experience variable, one-way ANOVA results indicate that the teachers' levels of professional development related to AT were statistically significantly different based on their years of teaching experience, $F(2,95)=3.32, p=.04$, as shown in Table 14. Thus, the teachers' levels of professional development related to AT were slightly different based on mean scores: $5-10$ years $(M=6.71, S D=1.92), 11$ 16 years $(M=7.27, S D=1.83)$, and over 16 years $(M=7.91, S D=1.52)$. In contrast, Table 15 displays results of the Bonferroni test analysis indicating that there was only one statistically significant difference between the teachers' levels of professional development related to AT based on their years of teaching experience. Teachers who had 5-10 years of teaching experience were significantly different $(p=.036)$ from teachers who had over 16 years of teaching experience. However, there was no statistically significant difference between teachers' other years of teaching experience. For the grade level variable, one-way ANOVA results indicate that the teachers' levels of professional development related to AT were not statistically significantly different based on the grade levels they taught, $F(2,95)=2.33, p=.102$, as shown in Table 14. Thus, the teachers' levels in professional development related to AT were slightly different based on mean scores: elementary school $(M=6.87, S D=2.04)$, middle school $(M=7.66, S D=1.04)$, and high school $(M=7.69, S D=1.61)$. In contrast, the results of the Bonferroni test analysis were not needed, as shown in Table 15. For the school location variable, one-way ANOVA results indicate that the teachers' levels of professional development related to AT were not statistically significantly different based on the locations of their schools, $F(2$, $95)=.158, p=.85$, as shown in Table 14. Thus, the teachers' levels of professional development related to AT were slightly different based on mean scores: small city $(M=7.12, S D=1.70)$, suburban region $(M=7.27$, $S D=2.57)$, and large city $(M=7.35, S D=1.85)$. In contrast, the results of the Bonferroni test analysis were not needed, as shown in Table 15.

\section{Results Related to RQ4}

The researcher used a simple linear regression to assess whether teachers' perceptions of AT predicted their AT knowledge and skills in educational environments. Results shown in Table 16 indicate that teachers' perceptions of AT significantly predicted their AT knowledge and skills, $\beta=.528, t(96)=3.52, p<.001$. Additionally, regression results suggest that teachers' perceptions of AT explained $11.5 \%$ of the variance, 
Table 15. Post hoc analysis (Bonferroni test) for teachers' responses based on education level, teaching experience, grade level, and school location variables

\begin{tabular}{|c|c|c|c|c|}
\hline Variables & & Mean difference & Std. error & Sig. \\
\hline \multicolumn{5}{|l|}{ Education level } \\
\hline \multirow[t]{3}{*}{ Diploma } & Bachelor's & 1.63000 & .67447 & .106 \\
\hline & Master's & 1.85000 & .86018 & .204 \\
\hline & Doctoral & 1.95000 & 1.03381 & .374 \\
\hline \multirow[t]{3}{*}{ Bachelor's } & Diploma & $-1.63000-$ & .67447 & .106 \\
\hline & Master's & .22000 & .61049 & 1.000 \\
\hline & Doctoral & .32000 & .83759 & 1.000 \\
\hline \multirow[t]{3}{*}{ Master's } & Diploma & $-1.85000-$ & .86018 & .204 \\
\hline & Bachelor's & $-.22000-$ & .61049 & 1.000 \\
\hline & Doctoral & .10000 & .99325 & 1.000 \\
\hline \multirow[t]{3}{*}{ Doctoral } & Diploma & $-1.95000-$ & 1.03381 & .374 \\
\hline & Bachelor's & $-.32000-$ & .83759 & 1.000 \\
\hline & Master's & $-.10000-$ & .99325 & 1.000 \\
\hline \multicolumn{5}{|c|}{ Teaching experience } \\
\hline \multirow[t]{2}{*}{$5-10$ years } & $11-16$ years & $-.56725-$ & .41937 & .538 \\
\hline & over 16 years & $-1.20614-*$ & .47014 & .036 \\
\hline \multirow[t]{2}{*}{$11-16$ years } & $5-10$ years & .56725 & .41937 & .538 \\
\hline & over 16 years & $-.63889-$ & .47517 & .546 \\
\hline \multirow[t]{2}{*}{ over 16 years } & $5-10$ years & $1.20614 *$ & .47014 & .036 \\
\hline & $11-16$ years & .63889 & .47517 & .546 \\
\hline \multicolumn{5}{|l|}{ Grade level } \\
\hline \multirow[t]{2}{*}{ Elementary } & Middle & $-.78947-$ & .52843 & .415 \\
\hline & High & $-.81511-$ & .43094 & .185 \\
\hline \multirow[t]{2}{*}{ Middle } & Elementary & .78947 & .52843 & .415 \\
\hline & High & $-.02564-$ & .59042 & 1.000 \\
\hline \multirow[t]{2}{*}{ High } & Elementary & .81511 & .43094 & .185 \\
\hline & Middle & .02564 & .59042 & 1.000 \\
\hline \multicolumn{5}{|l|}{ School location } \\
\hline \multirow[t]{2}{*}{ Large city } & Small city & .22984 & .41686 & 1.000 \\
\hline & Suburban regions & .08211 & .65351 & 1.000 \\
\hline \multirow[t]{2}{*}{ Small city } & Large city & $-.22984-$ & .41686 & 1.000 \\
\hline & Suburban regions & $-.14773-$ & .61411 & 1.000 \\
\hline \multirow[t]{2}{*}{ Suburban region } & Large city & $-.08211-$ & .65351 & 1.000 \\
\hline & Small city & .14773 & .61411 & 1.000 \\
\hline
\end{tabular}

Table 16. Linear regression analysis of teachers' perceptions of AT

\begin{tabular}{lccccc}
\hline \multicolumn{5}{c}{ Unstandardized coefficients } & Standardized coefficients \\
\hline Model & B & Std. Error & Beta & T & Sig. \\
(Constant) & 2.366 & 5.214 & & .454 & .651 \\
Per & .528 & .150 & .339 & 3.525 & .001 \\
R square $=.115$ & & & & & \\
\hline
\end{tabular}

$R 2=.115, F(1,96)=12.427, p<.001$ in teachers' AT knowledge and skills. Specifically, each additional unit in teachers' perceptions of AT was associated with a .528-point increase in teachers' AT knowledge and skills.

\section{DISCUSSION}

\section{RQ1}

Most of the teachers agreed with the statement I know how to arrange the classroom environment to facilitate the use of AT while other teachers disagreed with the statement I know how to use a variety of AT devices to support students with intellectual disabilities. Furthermore, most of the teachers agreed with the statement Professionals should conduct AT evaluation regularly to determine whether or not their students 
need AT. This finding is important because it aligns with research by Tamakloe and Agbenyega (2017) indicating teachers' need for professional knowledge and practice to impact student learning. Similarly, Alkahtani (2013) noted teachers' lack of AT knowledge and skills and asserted that teachers' attitudes and beliefs teachers play an essential role in avoiding, selecting, or implementing AT.

Results of the current research indicate that $27.6 \%$ of these teachers had no training in implementing various types of AT which means most of these teachers did not have AT knowledge and skills. Also, a majority of these teachers (54.1\%) indicated that they had beginner knowledge of using AT while $10.2 \%$ had no knowledge. Additionally, half of the teachers (51\%) indicated that they had beginner skills in using AT, while $11.2 \%$ had no skills. Moreover, two-thirds of the teachers (66.3\%) expressed that they didn't work with others on AT considerations while $33.7 \%$ said they worked with others in this regard. This finding aligns with Ribeiro and Moreira's (2010) finding that a majority of teachers had no AT training. Similarly, Alkahtani's (2013) study indicated that $93 \%$ of teachers had no AT training and that they lacked AT knowledge and skills.

\section{RQ2}

Comparison of AT knowledge and skills scores based on gender indicate that female special education teachers in this study had greater levels of AT knowledge and skills than males. However, this finding does not support Almulla (2019) finding that gender impacted teachers' AT use. On the other hand, there was statistically significant difference between special education teachers based on training. However, it is important to consider the unequal distribution of training in AT, as $72.4 \%$ of the training in AT variable was in teachers who didn't have any training; this could be the reason why there was a statistically significant difference. The mean for teachers who had AT training (24.7) was higher than for teachers who didn't have training in AT (19.1\%). These findings align with the previous studies of Ribeiro and Moreira (2010) and Alkahtani (2013) that a majority of teachers had no AT training.

This study reveals that teachers' levels of AT knowledge and skills were statistically significantly different based on their levels of education, $F(3,94)=4.25, p=0.007$. Comparison of teachers' AT knowledge and skills revealed that teachers who had earned diplomas were significantly different $(p=0.01)$ from teachers who held doctoral degrees. In addition, teachers who held bachelor's degrees were significantly different $(p=0.04)$ from teachers who held doctoral degrees. This finding is important because it does not align with Almulla (2019) research suggesting that level of education did not impact teachers' AT use. In contrast, the current findings do align with other research (i.e., Bell et al., 2010; Van Laarhoven \& Conderman, 2011) that found that teachers who had attended college-level courses in AT had high levels of AT knowledge and use.

The current study found statistically significant differences in teachers' AT knowledge and skills based on their years of teaching experience, $F(2,95)=4.24, p=0.017$. Comparisons revealed only one statistically significant difference between teachers' levels of AT knowledge and skills based on their years of teaching experience. Teachers who had 5-10 years of teaching experience were significantly different $(p=0.016)$ from teachers who had over 16 years of teaching experience. This finding contradicts Onivehu et al.'s (2017) conclusion that teaching experience did not impact teachers' attitudes toward using AT.

There were no statistically significant differences in teachers' AT knowledge and skills based on grade levels they taught, $F(2,95)=.390, p=.678$. However, it is important to consider the unequal distribution of grade levels, as $58.2 \%$ of reported grade levels taught were elementary school, which could be the reason for there was no difference.

This study reveals that teachers' levels of AT knowledge and skills were statistically significantly different based on their schools' locations, $F(2,95)=4.13, p=.019$. Teacher comparisons revealed that teachers who taught in large cities were significantly different $(p=.01)$ from teachers who taught in suburban regions. In addition, teachers who taught in small cities were marginally significantly different $(p=.05)$ from teachers who taught in suburban regions. This finding contrasts with previous study findings (Alkahtani, 2013; Almulla, 2019) that school location was not a significant predictor of teachers' AT knowledge and skills. In contrast, the current results align with previous studies concluding that rural schools were likely to face unique AT challenges compared to other locations (Ault et al., 2013, Davis et al., 2013; Sutton et al., 2014). 


\section{RQ3}

The third study objective was to determine if there were any significant differences in Saudi teachers' professional development related to AT based on the gender, training, level of education, years of experience, grade level, and school location variables. Results of comparisons of professional development scores based on gender indicate that female special education teachers had a greater level of AT professional development than males. This finding aligns with research by Almulla (2019) suggesting that gender impacts teachers' AT use. With regard to the training in AT variable, results indicate that there was no statistically significant difference between special education teachers' professional development depending on training. However, it is important to consider that there was not an equal representation of training in AT, as $72.4 \%$ of the training variable was in teachers who didn't have training, which could be the reason why there was no statistically significant difference. Results of previous studies show that a majority of teachers had no AT training (Alkahtani, 2013; Ribeiro \& Moreira, 2010).

This study reveals that there were no statistically significant differences in teachers' professional development based on level of education. However, it is important to consider that unequal distribution of education level, as $76.5 \%$ of the education level variable was in teachers who had completed a bachelor's degree, which could have affected the results. This finding aligns with research by Almulla (2019) who concluded that level of education did not impact teachers' AT use. In contrast, results of previous studies show the opposite of the current study's finding that high levels of AT knowledge and use were explored by teachers who had attended college-level courses in AT (Bell et al., 2010; Van Laarhoven \& Conderman, 2011).

With regard to the years of teaching experience variable, result indicate only one statistically significant difference between the teachers' levels in professional development related to AT based on their years of teaching experience. Teachers who had 5-10 years of teaching experience were significantly different $(p=.036)$ from teachers who had over 16 years of teaching experience. This finding contradicts that of Onivehu et al. (2017) who found that teaching experience did not impact teachers' attitudes toward using AT.

This study reveals no statistically significant differences in teachers' professional development based on grade levels taught. However, it is important to consider that there was not an equal representation of grade levels, as $58.2 \%$ of the teachers taught in elementary school, which could have affected the results.

This study also reveals no statistically significant differences in teachers' professional development based on the locations of their schools. However, it is important to consider that there was not an equal representation of school locations, as $57.1 \%$ of the teachers' schools were in small cities, which could have affected the results. This finding aligns with research by Almulla (2019) and Alkahtani (2013) that suggested that school location was not a significant predictor in teachers' AT knowledge and skills.

\section{RQ4}

This study's last question aimed to determine if teachers' perceptions of AT predicted their AT knowledge and skills. Results indicate that teachers' perceptions of AT significantly predicted teachers' AT knowledge and skills in educational environments. Additionally, regression results suggest that teachers' perceptions of AT explained $11.5 \%$ of the variance in teachers' AT knowledge and skills. Specifically, each additional unit in these teachers' perceptions of AT was associated with a .528-point increase in their AT knowledge and skills. This finding aligns with Almulla (2019) conclusion that teachers' perceptions of AT were a positive significant predictor of their AT knowledge and skills. Also, Flanagan and colleagues (2013) and Alkahtani (2013) explained that teachers' attitudes toward AT were a significant predictor of their selecting and implementing AT.

\section{CONCLUSIONS AND RECOMMENDATIONS}

The purpose of this study was to examine overall levels of teachers' knowledge and skills related to using AT, to describe differences in these levels based on teachers' demographic characteristics, and to determine if 
teachers' perceptions of AT were a significant predictor of teachers' knowledge and skills related to using AT for students with ID in Saudi Arabia. The findings indicate that most of the teachers had beginner levels of AT knowledge and skills. Results also show that teachers' levels of AT knowledge and skills were statistically significantly different based on gender, training, level of education, teaching experience, and school location. Also, there were statistically significant differences in teachers' professional development based on gender and teaching experience. Results also indicate that teachers' perceptions of AT significantly predicted teachers' knowledge and skills related to AT use in educational environments.

As mentioned previously, there is a lack of studies about teachers' knowledge and skills related to using AT in the KSA. The current study addressed a gap in the research by addressing the level of Saudi Arabian teachers' attitudes toward AT use for students with ID. This may bring attention to the issues that might help to raise awareness of some of the barriers that inhibit special education teachers.

Furthermore, future research is needed to examine alternative research methods because each method allows researchers to explore different questions and discover new findings. The results of this study point especially to the need to include qualitative measures while studying levels of teachers' knowledge and skills related to using AT. Additionally, more research could expand on this study to include a more representative sample to obtain more information and generalize this study's results. This could address the lack of statistical significance in some of this study's findings.

Furthermore, a variety of evidence-based practices that encourage students with disabilities to be successful in their tasks play an essential role in special education teams' AT implementation. Thus, to improve services and implement AT, a specialized AT team must develop effective plans to meet the specific needs of individuals with or without disabilities. Implementing AT usually requires collaboration and reliance on existing frameworks, such as the SETT Framework, Wisconsin Assistive Technology Initiative (WATI), and Quality Indicators for Assistive Technology (QIAT), to promote the effective use of AT.

Author notes: The author approves final version of the article.

Funding: The author received no financial support for the research and/or authorship of this article.

Declaration of interest: The author declares no competing interest.

Data availability: Data generated or analysed during this study are available from the author on request.

\section{REFERENCES}

Aldosari, M. S., \& Pufpaff, L. A. (2014). Sources of stress among parents of children with intellectual disabilities: A preliminary investigation in Saudi Arabia. The Journal of Special Education Apprenticeship, 3(1), 1-21.

Alfaraj, A., \& Kuyini, A. (2014). The use of technology to support the learning of children with down syndrome in Saudi Arabia. World Journal of Education, 4(6), 42-53. https://doi.org/10.5430/wje.v4n6p42

Alkahtani, K. D. (2013). Teachers' knowledge and use of assistive technology for students with special educational needs. Journal of Studies in Education, 3(2), 65-86. https://doi.org/10.5296/jse.v3i2.3424

Almulla, A. A. (2019). Elementary school teachers' attitudes toward using high-tech assistive technology for students with learning disabilities in Saudi Arabia [Unpublished doctoral dissertation]. Concordia University Chicago.

Alotaibi, F., \& Almalki, N. (2016). Saudi teachers' perceptions of ICT implementation for students with autism spectrum disorder at mainstream schools. Journal of Education and Practice, 7(5), 116-124.

Applequist, K. L. (2009). Parent perspectives of special education: Framing of experiences for prospective special educators. Rural Special Education Quarterly, 28(2), 3-16. https://doi.org/10.1177/ 875687050902800202 
Ault, M. J., Bausch, M. E., \& McLaren, E. M. (2013). Assistive technology service delivery in rural school districts. Rural Special Education Quarterly, 32(2), 15-22. https://doi.org/10.1177/ 875687051303200204

Battal, Z. M. B. (2016). Special education in Saudi Arabia. International Journal of Technology and Inclusive Education, 5(2), 880-886. https://doi.org/10.20533/ijtie.2047.0533.2016.0113

Bell, S. M., Cihak, D. F., \& Judge, S. (2010). A preliminary study: Do alternative certification route programs develop the necessary skills and knowledge in assistive technology? International Journal of Special Education, 25(3), 110-118.

Bouck, E. C., Maeda, Y., \& Flanagan, S. M. (2012). Assistive technology and students with high-incidence disabilities understanding the relationship through the NLTS2. Remedial and Special Education, 33(5), 298-308. https://doi.org/10.1177/0741932511401037

Bruinsma, A. M. (2011). Implementation of assistive technology in the classroom. [Unpublished master's thesis]. St. John Fisher College.

Creswell, J. W. (2012). Educational research: Planning, conducting, and evaluating quantitative and qualitative research. Pearson.

Davis, T. N., Barnard-Brak, L., \& Arredondo, P. L. (2013). Assistive technology: Decision-making practices in public schools. Rural Special Education Quarterly, 32(4), 15-23. https://doi.org/10.1177/ 875687051303200403

Erdem, R. (2017). Students with special educational needs and assistive technologies: A literature review. TOJET: The Turkish Online Journal of Educational Technology, 16(1), 128-146.

Flanagan, S., Bouck, E. C., \& Richardson, J. (2013). Middle school special education teachers' perceptions and use of assistive technology in literacy instruction. Assistive Technology, 25(1), 24-30. https://doi.org/10.1080/10400435.2012.682697

Kurth, J. A., \& Keegan, L. (2014). Development and use of curricular adaptations for students receiving special education services. The Journal of Special Education, 48(3), 191-203. https://doi.org/10.1177/ 0022466912464782

Merriam-Webster. (n.d.). Attitude. Merriam-Webster.com dictionary. https://www.merriamwebster.com/dictionary/attitude

Ministry of Education of Saudi Arabia. (2018). General Department of Special Education. https://departments.moe.gov.sa/EducationAgency/RelatedDepartments/SPECIALEDUCATION/Pages/ Hearingdisability.aspx

Okolo, C. M., \& Diedrich, J. (2014). Twenty-five years later: How is technology used in the education of students with disabilities? Results of a statewide study. Journal of Special Education Technology, 29(1), 1-20. https://doi.org/10.1177/016264341402900101

Onivehu, A. O., Ohawuiro, O. E., \& Oyeniran, B. J. (2017). Teachers' attitude and competence in the use of assistive technologies in special needs schools. Acta Didactica Napocensia, 10(4), 21-32. https://doi.org/10.24193/adn.10.4.3

Ribeiro, J., \& Moreira, A. (2010). ICT training for special education frontline professionals. International Journal of Emerging Technologies in Learning, 5(2), 55-59. https://doi.org/10.3991/ijet.v5s2.1218

Sibon-Macarro, T., Abou-Rjaily, K., Stoddard, S., Sandigo, A., Peterson, P., \& Ross, V. (2014). Rural perspectives of models, services, and resources for students with hearing impairments. Rural Special Education Quarterly, 33(4), 24. https://doi.org/10.1177/875687051403300404 
Sutton, J. P., Bausmith, S. C., O’Connor, D. M., Pae, H. A., \& Payne, J. R. (2014). Building special education teacher capacity in rural schools: Impact of a grow your own program. Rural Special Education Quarterly, 33(4), 14.

Tamakloe, D., \& Agbenyega, J. S. (2017). Exploring preschool teachers' and support staff's use and experiences of assistive technology with children with disabilities. Australasian Journal of Early Childhood, 42(2), 29-36. https://doi.org/10.23965/AJEC.42.2.04

Teddlie, C., \& Tashakkori, A. (2009). Foundations of mixed methods research: Integrating quantitative and qualitative approaches in the social and behavioral sciences. SAGE.

The IRIS Center for Training Enhancements. (2010). Assistive technology. http://iris.peabody.vanderbilt.edu/ module/at/

Utley, C., Obiakor, F., \& Bakken, J. (2011). Culturally responsive practices for culturally and linguistically diverse students with learning disabilities. Learning Disabilities: A Contemporary Journal, 9(1), 5-18.

Van Laarhoven, T., \& Conderman, G. (2011). Integrating assistive technology into special education teacher preparation programs. Journal of Technology and Teacher Education, 19(4), 473-497.

Wojcik, B. W., \& Douglas, K. H. (2012). Illinois assistive technology guidance manual. http://www.isbe.state.il.us/spec-ed/pdfs/assist-tech-guidance-manual.pdf

Yell, M. L. (2016). The law and special education. Pearson Education, Inc.

Yusuf, M. O., \& Fakomogbon, M. (2008). Availability, teachers' awareness and attitude towards the use of assistive technologies in special schools in Kwara State, Nigeria. In J. Luca \& E. R. Weippl (Eds.), Proceedings of the world conference on educational multimedia, hypermedia and telecommunications 2008 (pp. 6228-6235).

Correspondence: Sultan Aldehami, Department of Special Education, College of Science and Arts, Qassim University, Ar Rass, Saudi Arabia. E-mail: s.aldehami@qu.edu.sa 